\title{
Real World Cost-of-Illness Evidence in Hepatitis C Virus: A systematic review
}

\author{
T. Joseph Mattingly II ${ }^{1}$ (D) Bryan L. Love ${ }^{2}$ (D) Bilal Khokhar ${ }^{3}$ (D)
}

Published online: 12 June 2020

(c) The Author(s) 2020

\begin{abstract}
Background The introduction of direct-acting antivirals (DAAs) represents a potential clinical cure for hepatitis $\mathrm{C}$ virus (HCV) infection. Identification of costs associated with different stages of untreated disease through cost-of-illness (COI) evaluation helps inform policy decisions and cost-effectiveness analyses (CEAs). This study's objective was to review published real-world costs for patients with $\mathrm{HCV}$ to estimate the COI across different stages of disease progression.

Methods A literature search of EMBASE, Scopus, and PubMed from January 1, 2010 to August 31, 2019 was conducted to identify real-world evidence related to HCV. Data extraction included citation details, population, study type, costing method used, currency and inflation adjustments, and disease-specific costs. Standardized costing method categories (sum all medical, sum diagnosis specific, matching, regression, other incremental, and other total) were assigned. The risk of bias was assessed at the outcome level for influence on costs attributable to HCV.

Results The search strategy identified 278 studies, with 31 included in the final review after inclusion and exclusion criteria were applied. Retrospective cohorts (77\%) and cross-sectional analyses (16\%) were most frequently encountered. Sum Diagnosis Specific was the most common costing method (39\%), followed by Regression (32\%). Of the 31 studies analyzed, $35 \%$ included costs that would be included in a societal model. Costs were identified for various stages and complications related to HCV disease progression. Several studies included were determined to have a high (48\%) or moderate risk (42\%) of bias related to COI estimates.

Conclusion Cost estimates for formal, informal, and non-health care services were identified in this review, but several challenges still exist in fully quantifying HCV burden. Future modeling studies including cost inputs should critically evaluate the risk of bias based on costing methods and data sources.
\end{abstract}

Electronic supplementary material The online version of this article (https://doi.org/10.1007/s40273-020-00933-3) contains supplementary material, which is available to authorized users.

T. Joseph Mattingly II

jmattingly@rx.umaryland.edu

1 Department of Pharmaceutical Health Services Research, University of Maryland School of Pharmacy, 220 Arch Street, 12th Floor, Baltimore, MD 21201, USA

2 Department of Clinical Pharmacy and Outcomes Sciences, Center for Outcomes Research and Evaluation, University of South Carolina College of Pharmacy, Columbia, SC, USA

3 General Dynamics Information Technology, Silver Spring, MD, USA

\section{Key Points for Decision Makers}

Real-world evidence for the costs associated with hepatitis $\mathrm{C}$ virus exists for formal, informal, and non-health care services, enabling both health sector and societal perspective research approaches to determine cost-effectiveness.

Many cost estimates may have a moderate or high risk of bias and should be critically evaluated and adjusted prior to inclusion as an economic model input. 


\section{Introduction}

\subsection{Chronic Hepatitis C}

Chronic hepatitis $\mathrm{C}$ virus (HCV) infection has a global impact, with an estimated prevalence between 1 and 3\% depending on country and region [1]. Pharmacological innovations in the past decade, marked by the discovery of effective direct-acting antivirals (DAAs), have provided therapeutic options that frequently lead to a clinical cure, defined as sustained virologic response (SVR) [2-4]. The high cost of DAA treatment has spurred controversy regarding affordability as well as a significant number of cost-effectiveness analyses (CEAs) investigating the value of these new medication regimens [5-7]. Identification of costs associated with different stages of the untreated disease helps to inform the numerator for the resulting incremental cost-effectiveness ratio. Dorothy Rice's seminal paper published in 1967 helped spur the growth of cost-of-illness (COI) research to inform policy decisions and economic analyses [8]. As we focus on any particular disease, such as hepatitis $\mathrm{C}$, the COI methods used may play an important role in what costs are included, where in the course of the disease these costs occur, the reliability of estimates, and who bears the financial or economic burden [9-11].

\subsection{Cost-of-IIIness Methods}

In two previous systematic reviews of published COI studies across all diseases, costing methods (sum all medical, sum diagnosis specific, matching, regression, other incremental, and other total) have been categorized and described to aid in the interpretation and application of COI results [12, 13]. Sum All Medical and Sum Diagnosis Specific may be generally described as relatively simple costing approaches that identify patients with a given diagnosis and include all medical costs or all costs related to the diagnosis in question [14]. Matching, Regression, Other Incremental, and Other Total may be generally described as more complex approaches to costing as they attempt to address potential confounding and bias in COI estimates [14]. In the case of $\mathrm{HCV}$, a hypothetical COI study might identify all patients recruited through a substance-abuse program. A simple costing method may describe that population accurately but may bias the cost estimate attributable to HCV by not considering other variables observed in that patient sample compared to the full HCV population. Rather than dismiss Sum All Medical or Sum Diagnosis Specific methods, these predominantly descriptive approaches may still be useful depending on the research question of the study. For the purposes of this review, all costing approaches may be informative, but should be assessed in the context of the question of COI attributable to $\mathrm{HCV}$ disease.

\subsection{Study Objectives}

The aim of this study was to systematically review all published studies that captured real-world costs for patients with HCV to estimate the COI of HCV across different stages of disease progression. Additionally, this study aims to describe the study methods used to estimate the $\mathrm{COI}$ and provide recommendations for future economic evaluations for $\mathrm{HCV}$ and its treatment.

\section{Methods}

This systematic review was conducted in accordance with the Preferred Reporting Items for Systematic Reviews and Meta-Analyses (PRISMA) recommendations [15].

\subsection{Search Strategy}

On August 31, 2019, we conducted a literature search to identify COI studies related to $\mathrm{HCV}$ infection using EMBASE, Scopus, and PubMed. The phrase "cost of illness" was found in the Medical Subject Headings (MeSH) for PubMed and Emtree headings for EMBASE and was combined with "hepatitis C" for these databases. The "explode" function was enabled within EMBASE to enable a broader search of the Emtree headings. For Scopus, a combination of "cost of illness" and "hepatitis C" was used to search abstract/title/keywords. Searches in all three databases were limited to the period 2010-present. The term "cost of illness" was used over the more generic "cost" heading to narrow the search within health economics. See the "Online Supplement" in the electronic supplementary material for more information on the review search strategies.

\subsection{Selection Criteria}

Studies were included if they were full-text original research or systematic reviews utilizing real-world observations to estimate the costs related to HCV. Therefore, modeling studies that simulated cost estimates or burden-of-illness studies solely focused on epidemiology with no costs reported were excluded. Studies were also excluded if HCV costs were aggregated with other liver diseases (hepatitis A or B) where the HCV-specific costs were unknown.

Abstract screening was completed by all three authors, with two votes required for all abstracts. Any disagreements were discussed by the full research team until full consensus was reached. Full-text articles were retrieved and reviewed 
by one author (TJM), and all exclusions at the full-text step required agreement from the full research team.

\subsection{Data Extraction}

Data extraction included article citation details (year, authors, title), country of HCV patients observed, population characteristics, sample size (if applicable), study description, study years included, presence of societal costs (yes/ no), description of costing method, costing method category, analysis type, results (detail), funding source, currency and inflation costs adjustments, and disease-specific costs reported. Costing method categories were defined previously in a systematic review of COI studies for all diseases by Onukwugha et al. [13]. For extraction of HCV costs, all health sector and societal perspective costs were extracted as reported by the study authors. Health sector and societal perspective costs were identified based on formal, informal, and non-health impact definitions provided by the Second Panel on Cost-Effectiveness in Health and Medicine [16] (Table 1).

\subsection{Evidence Synthesis}

To compare costs reported across studies, all costs were converted to United States dollars (USD) and inflated to December 31, 2019 using the Bureau of Labor Statistics Consumer Price Index (CPI) for medical care services [17].

Table 1 Hypothetical impact inventory for cost-effectiveness analyses in hepatitis C [51]

\begin{tabular}{|c|c|c|c|}
\hline \multirow[t]{2}{*}{ Sector } & \multirow[t]{2}{*}{ Type of impact } & \multicolumn{2}{|l|}{ Perspective } \\
\hline & & Health care & Societal \\
\hline \multirow[t]{2}{*}{ Formal health } & Direct medical costs (medications, laboratory testing, inpatient, outpatient, etc.) & Yes & Yes \\
\hline & Direct health effects (longevity, health-related quality of life, adverse events, etc.) & Yes & Yes \\
\hline Informal health & Indirect costs (patient and caregiver time related to care, transportation, etc.) & NA & Yes \\
\hline \multirow[t]{2}{*}{ Non-health } & Labor market earnings lost (absenteeism) & NA & Yes \\
\hline & Productivity loss (presenteeism) & NA & Yes \\
\hline
\end{tabular}

NA not applicable

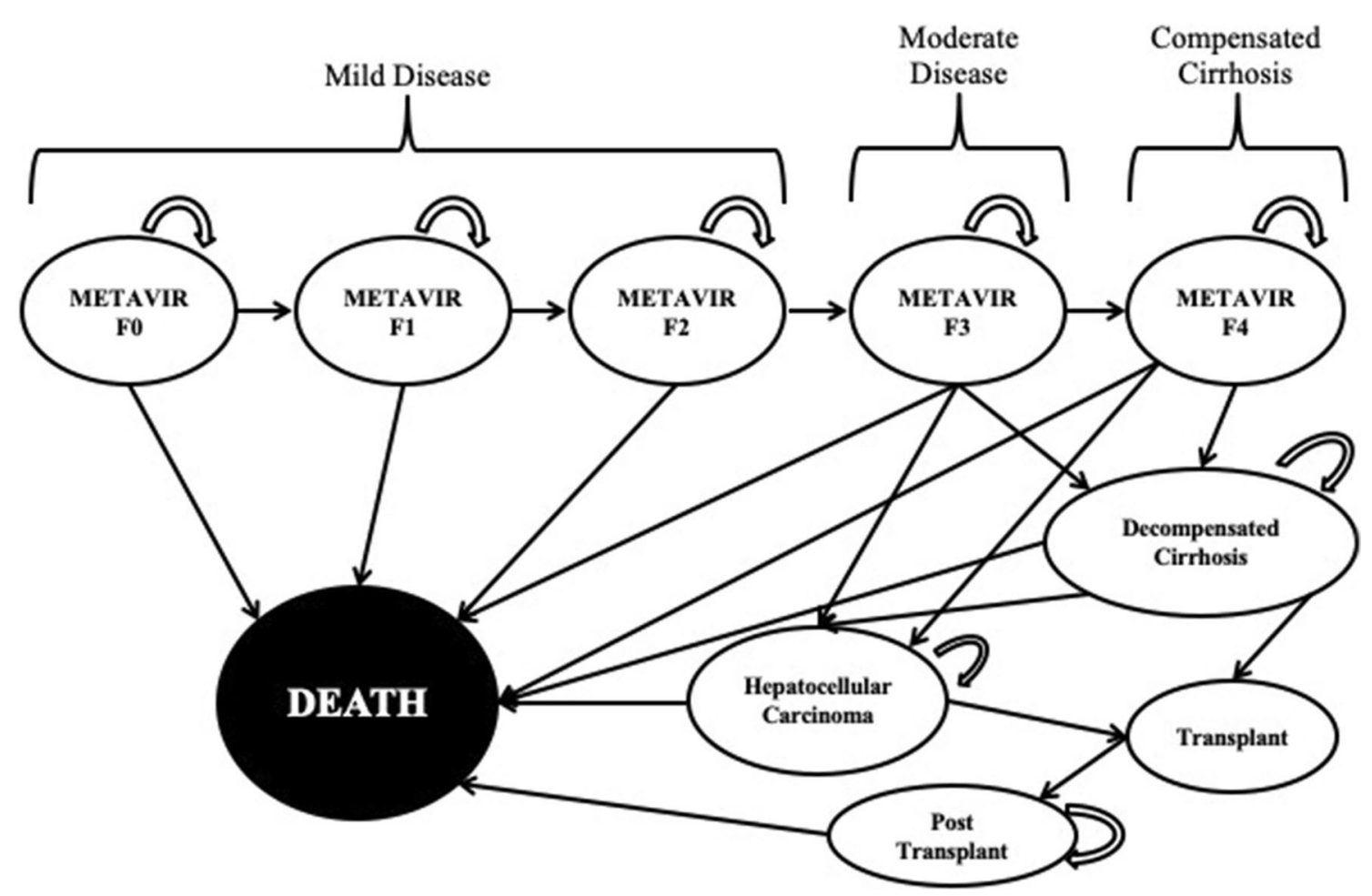

Fig. 1 Health state model representing natural progression of liver disease for patient with hepatitis C 
Costs extracted were stratified by health states commonly used in economic evaluation for DAAs in HCV (Fig. 1). Due to the expected heterogeneity of costing methods, authors determined a priori to present costs reported without combining multiple studies. Exploratory bivariate analyses were conducted to determine any associations between key variables. Costing methods were further categorized as simple (sum all medical, sum diagnosis specific) and complex (regression, matching, multiple) for comparison [14]. Additionally, analysis types were categorized as simple (descriptive statistics) and complex (regression, matching, multiple) for comparison.

\subsection{Risk of Bias Assessment}

In accordance with PRISMA recommendations, we assessed the risk of bias within included studies at the outcome level, which required a consensus from the full research team. Specifically, the authors considered how study methods may have influenced costs attributable to $\mathrm{HCV}$ for the purposes of this review. Qualitatively, we described the potential sources of bias and rated studies as being at low, moderate, or high risk of bias. The costing method categorization aided in the risk of bias assessment, as more complex costing methods (e.g., Matching, Regression, and Other Incremental) may reduce certain types of bias in the resulting cost appropriated to disease $[13,14]$. Authors reached agreement that studies reporting descriptively with little to no statistical adjustments for cost estimates, no reported method of incorporating price inflation, or unadjusted cost sources (e.g., wholesale acquisition costs for drug prices, hospital charges rather than actual paid amounts) would produce a high risk of bias. Meanwhile, studies that attempted to control for some of these factors, but not all, would be rated as having moderate risk. Source of funding was discussed as a potential source of bias; however, the authors agreed it was difficult to assess bias based on funding source and felt more weight should be given to the stated methods. Therefore, funding source was not included in the final assessment of risk of bias. Based on this categorization, a risk of bias rating was proposed by one reviewer (TJM) with rationale described prior to group discussion. Proposed ratings and rationale were reviewed and discussed by all three authors for final risk of bias ratings requiring unanimous consent. Exploratory bivariate analyses were conducted to assess risk of bias and other key variables (e.g., inclusion of societal costs, presence of industry funding, US/other). All statistical analyses were performed in R version 3.5.3 [18].
Fig. 2 Preferred reporting items for systematic reviews and meta-analyses (PRISMA) diagram. PICOS Population, Intervention, Comparator, Outcomes, Setting

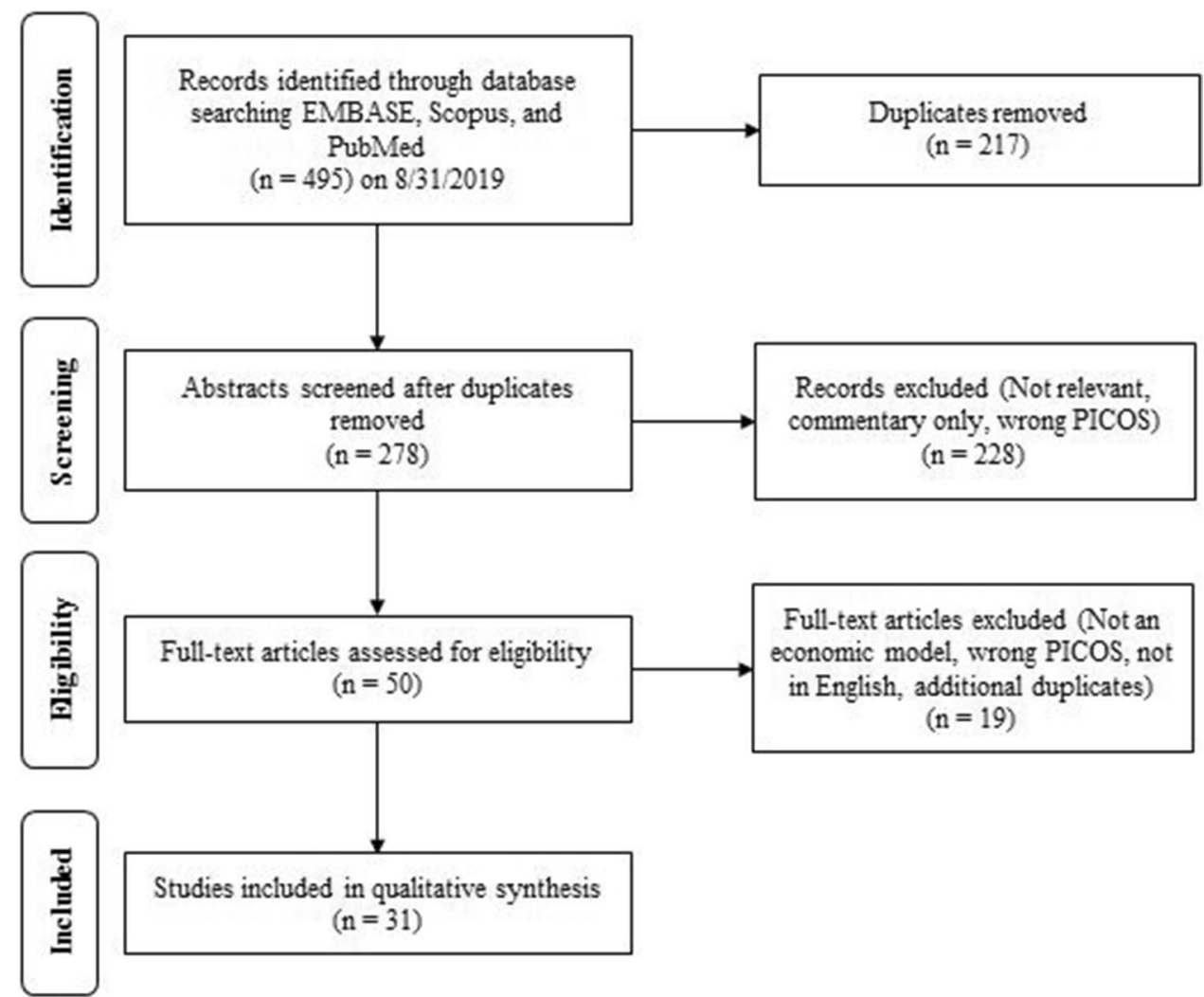




\section{Results}

\subsection{Overview of Studies}

The search strategy identified 495 records in EMBASE, Scopus, and PubMed, yielding 278 unique studies after duplicates were removed (Fig. 2). Of the 278 unique studies, there were 35 inclusion/exclusion conflicts during title and abstract screening (12.6\%) that required additional discussion for full author agreement. After title and abstract screening, 50 full-text manuscripts were assessed for eligibility. During full-text assessment, an additional 19 studies were excluded. Finally, 31 studies were included with full author agreement in the review for evidence synthesis [19-49]. Several countries were identified within the included studies, with the United States being identified the most frequently $(42 \%, 13 / 31)$ and multiple countries identified in two or fewer studies (Fig. 3).

\subsection{Methodological Heterogeneity}

The most frequent study type found in this review utilized a retrospective cohort design $(77 \%, 24 / 31)$, followed by crosssectional $(16 \%, 5 / 31)$. There were two previously published systematic reviews (6\%) that met the inclusion criteria [28, 45]. In terms of costing method, Sum Diagnosis Specific was the most common $(39 \%, 12 / 31)$, with Regression as the next most common (32\%, 10/31). Sum All Medical (10\%,
$3 / 31)$ and Matching $(6 \%, 2 / 31)$ were found less frequently, and four studies (13\%) used multiple methods to estimate costs (Table 2). In addition to costing method heterogeneity, methods varied in several areas, including data sources, population focus, presence of a control group for comparison, and accounting for net paid amount for health services or medications versus charged amounts.

\subsection{Societal Perspective Costs}

Of the 31 studies included, 35\% (11/31) included costs that would be included in a societal perspective model [16]. Absenteeism, presenteeism, patient time, caregiver time, and travel were identified costs (Table 4 ) associated with different stages of HCV infection [20, 28, 33, 34, 37, 41-44, 46, 49]. We did not identify any costs measured in the literature related to social services, legal or criminal justice, education, housing, environment, friction costs, or other unique societal perspective costs [16]. No associations were found between studies that reported societal costs and other key variables extracted (Table 5).

\subsection{Health-State Specific Costs}

Costs were identified for various stages of $\mathrm{HCV}$ disease progression, from no HCV (i.e., controls) through advanced liver fibrosis, compensated cirrhosis, decompensated cirrhosis, hepatocellular carcinoma, and liver transplant (Tables 3,

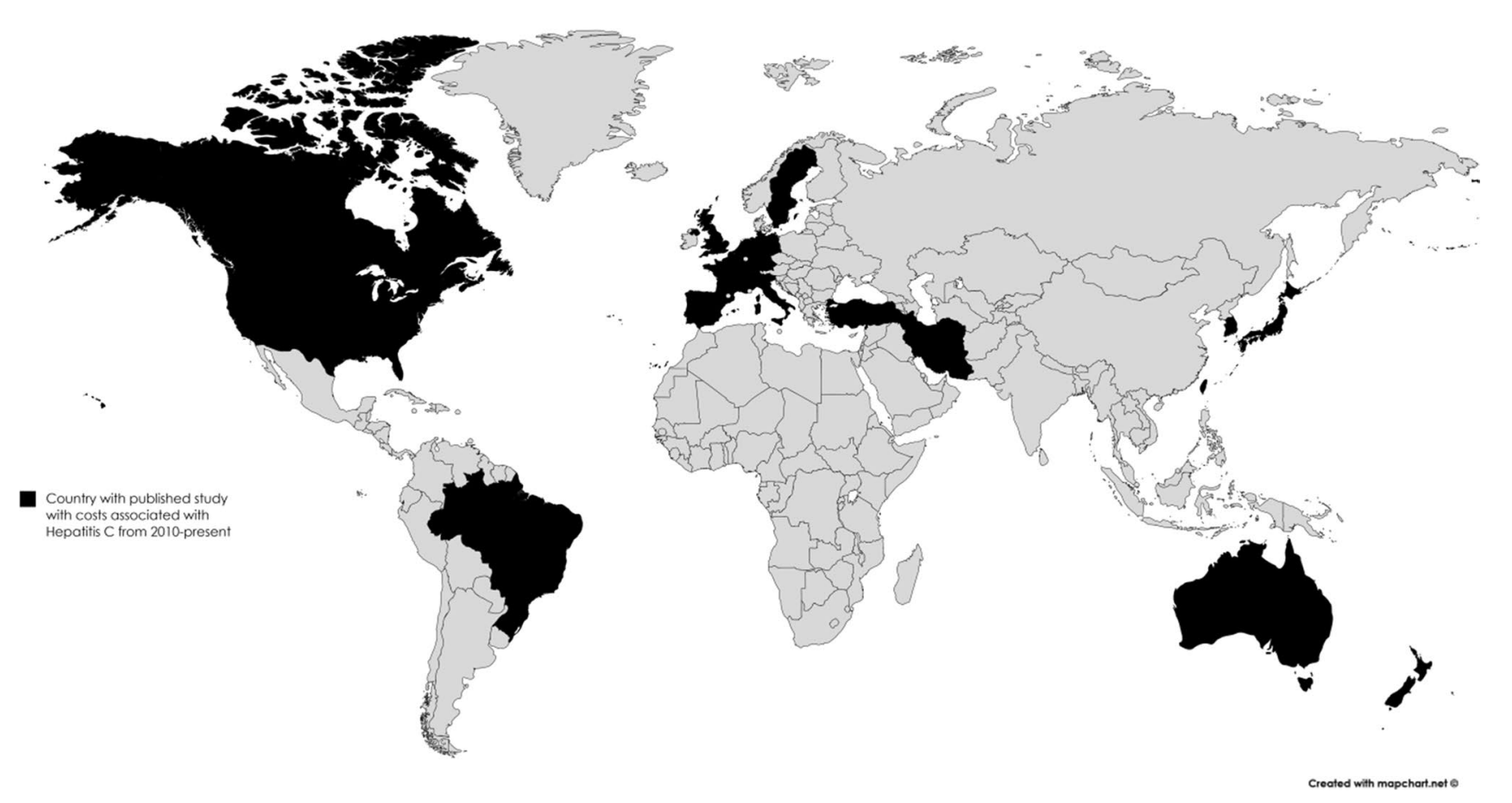

Fig. 3 Countries identified within published studies identifying costs associated with hepatitis C from 2010 to present [61] 


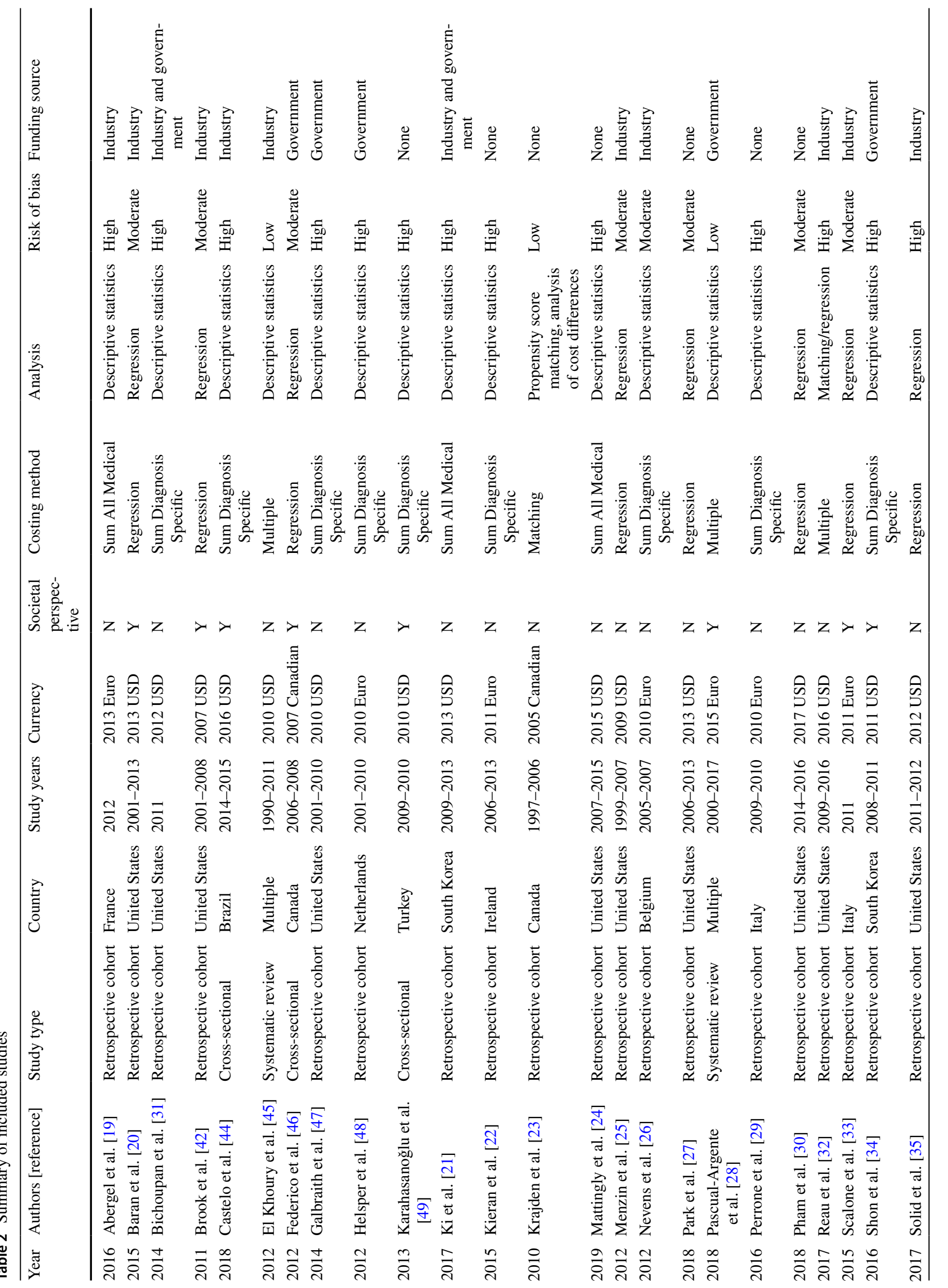


4). We did not identify costs associated with specific METAVIR fibrosis stages F0-F4, but rather costs observed by researchers were reported as either mild (F0-F2), moderate (F3), or compensated cirrhosis (F4) [50]. Health sector and societal cost estimates varied within and across natural progression health states from Fig. 1. In 2019 USD, all medical costs for non-HCV controls ranged from $\$ 952$ to $\$ 2164$ annually. Mild disease costs for all medical costs ranged from $\$ 477$ to $\$ 5505$ per year. Compensated cirrhosis all medical costs ranged from $\$ 5162$ to $\$ 7732$ per year. Decompensated cirrhosis and hepatocellular carcinoma had much greater variability for all medical costs, ranging from $\$ 4970$ to $\$ 63,080$ per year and $\$ 4396$ to $\$ 110,495$ per year, respectively. The cost of liver transplant also varied widely, ranging from $\$ 20,127$ to $\$ 578,758$ in the year of the transplant, with much smaller maintenance costs (\$7009-\$8224/ year) in years $>1$ year after transplant.

\subsection{Risk of Bias for Cost Estimates}

Authors evaluated each study for risk of bias specific to the reported costs associated with $\mathrm{HCV}$ disease and rated the majority of studies either high risk $(15 / 31,48 \%)$ or moderate risk $(13 / 31,42 \%)$. Only three studies $(3 / 31,10 \%)$ were given low risk scores, two of which were systematic reviews that included multiple country estimates [23, 28, 45]. Source of study funding was discussed as a possible variable to consider for bias, but the authors preferred to report funding separately for the reader to consider rather than make any judgments based on funder (Table 2). There was no association between societal perspective costs reported and risk of bias (Table 5).

\section{Discussion}

This systematic review included 31 studies that reported costs associated with HCV and descriptively reported evidence across health states commonly used in the development of CEAs for treatment in this population. Additionally, we categorize costs reported according to the recommended health sector and societal perspectives and assess potential risks of bias in these cost estimates [15, 51].

One of the most significant issues that CEA researchers must consider before reconstructing the commonly used HCV Markov process tied to METAVIR stage progression is the lack of real-world evidence for costs associated with the individual stage level (F0-F4) [50]. In a prior review of modeling approaches for CEAs in HCV, Chhatwal et al. reported 97\% (35/36) of published HCV models used a Markov design with 58\% (21/36) built in terms of METAVIR staging [7]. Using the METAVIR framework for transitioning between health states has 
Table 3 Cost-of-illness estimates for health sector perspective stratified by health state for hepatitis C

\begin{tabular}{|c|c|c|c|c|c|}
\hline Health state & Cost type & $\begin{array}{l}\text { Annual health sector cost } \\
\text { estimates (2019 USD) }\end{array}$ & $\mathrm{SD} / \mathrm{SE}$ & $N$ & Source \\
\hline \multirow[t]{2}{*}{ No HCV } & All medical & 952 & 2007 & 286 & [41] \\
\hline & All medical & 2164 & 4 & 727,588 & [20] \\
\hline \multirow[t]{2}{*}{ Any active $\mathrm{HCV}$} & Inpatient & 2915 & NR & 23,214 & [21] \\
\hline & Outpatient & 1490 & NR & 23,214 & [21] \\
\hline Post-SVR & All medical & $23-104$ & NR & 28 & [22] \\
\hline \multicolumn{6}{|l|}{ Disease severity } \\
\hline \multirow[t]{11}{*}{ Mild (F0-F2) } & All medical & 5505 & 252 & 1007 & [20] \\
\hline & All medical & 4204 & NR & 652 & [33] \\
\hline & All medical & 691 & NR & 166 & [43] \\
\hline & All medical & $477-684$ & NR & 40 & [22] \\
\hline & Inpatient & $39-1,616$ & NR & 51 & [37] \\
\hline & Inpatient & 5436 & NR & 1193 & [25] \\
\hline & Outpatient & 3468 & NR & 1193 & [25] \\
\hline & Outpatient & $2362-2889$ & NR & 51 & [37] \\
\hline & Pharmacy & 13,188 & NR & 1193 & [25] \\
\hline & Pharmacy & $20,481-27,514$ & NR & 51 & [37] \\
\hline & Pharmacy & 3432 & 147 & 1007 & [20] \\
\hline \multirow[t]{4}{*}{ Moderate (F3) } & All medical & $475-713$ & NR & 29 & [22] \\
\hline & Inpatient & $19-110$ & NR & 165 & [37] \\
\hline & Outpatient & $2362-2675$ & NR & 165 & [37] \\
\hline & Pharmacy & $21,765-25,810$ & NR & 165 & [37] \\
\hline \multirow[t]{7}{*}{ Compensated cirrhosis (F4) } & All medical & 5546 & 861 & 87 & [20] \\
\hline & All medical & 7732 & NR & 222 & [33] \\
\hline & All medical & 5162 & NR & 24 & [43] \\
\hline & Inpatient & $129-859$ & NR & 67 & [37] \\
\hline & Outpatient & $2229-2862$ & NR & 67 & [37] \\
\hline & Pharmacy & 5147 & 739 & 87 & [20] \\
\hline & Pharmacy & $19,418-26,867$ & NR & 67 & [37] \\
\hline \multirow[t]{7}{*}{ Decompensated cirrhosis } & All medical & 14,784 & 1339 & 256 & [20] \\
\hline & All medical & $4970-63,080$ & NR & NR & [45] \\
\hline & All medical & $5595-20,759$ & NR & 13 & [22] \\
\hline & Inpatient & $7927-28,221$ & NR & 32 & [37] \\
\hline & Outpatient & $1395-2150$ & NR & 32 & [37] \\
\hline & Pharmacy & $1321-7780$ & NR & 32 & [37] \\
\hline & Pharmacy & 4078 & 338 & 256 & [20] \\
\hline \multirow[t]{10}{*}{ Hepatocellular carcinoma } & All medical & 39,986 & 14,031 & 17 & [20] \\
\hline & All medical & 20,059 & NR & 85 & [33] \\
\hline & All medical & 9649 & NR & 10 & [43] \\
\hline & All medical & $4396-110,495$ & NR & NR & [45] \\
\hline & All medical & $21,588-41,791$ & NR & 27 & [22] \\
\hline & Inpatient & 15,897 & NR & 7140 & [21] \\
\hline & Inpatient & 33,744 & NR & 73 & [25] \\
\hline & Outpatient & 3252 & NR & 73 & [25] \\
\hline & Outpatient & 6279 & NR & 7140 & [21] \\
\hline & Pharmacy & 5560 & 1823 & 17 & [20] \\
\hline \multirow[t]{6}{*}{ Liver transplant (year 1) } & All medical & 116,665 & 38,724 & 19 & [20] \\
\hline & All medical & $192,914-196,150$ & NR & 33 & [22] \\
\hline & All medical & $20,127-578,758$ & NR & NR & [45] \\
\hline & Inpatient & 72,664 & NR & 118 & [21] \\
\hline & Outpatient & 8899 & NR & 118 & [21] \\
\hline & Pharmacy & 8377 & 2539 & 19 & [20] \\
\hline \multirow[t]{3}{*}{ Liver transplant ( $>1$ year) } & All medical & $7009-8224$ & NR & 33 & [22] \\
\hline & Inpatient & 9078 & NR & 84 & [21] \\
\hline & Outpatient & 13,903 & NR & 84 & [21] \\
\hline
\end{tabular}

$H C V$ hepatitis $C$ virus, $N R$ not reported, $S D$ standard deviation, $S E$ standard error, $S V R$ sustained virologic response, USD US dollar 
Table 4 Cost-of-illness estimates for the societal perspective stratified by health state for hepatitis C

\begin{tabular}{|c|c|c|c|c|c|}
\hline Health state & Cost type & $\begin{array}{l}\text { Annual societal cost } \\
\text { estimates (2019 USD) }\end{array}$ & $\mathrm{SD} / \mathrm{SE}$ & $N$ & Source \\
\hline \multirow[t]{3}{*}{ No HCV } & Absenteeism & 1830 & 7136 & 286 & [41] \\
\hline & Absenteeism & 778 & 6 & 727,588 & {$[20]$} \\
\hline & Presenteeism & 4818 & 7968 & 286 & [41] \\
\hline \multirow[t]{3}{*}{ Any active $\mathrm{HCV}$} & Absenteeism & $1450-2,587$ & NR & NR & {$[28]$} \\
\hline & Absenteeism & 1910 & NR & 1223 & [42] \\
\hline & Presenteeism & $4309-10,081$ & NR & NR & [28] \\
\hline \multirow[t]{2}{*}{ Post-SVR } & Patient time & $191-422$ & NR & 148 & [46] \\
\hline & Caregiver time & 25-107 & NR & 148 & [46] \\
\hline \multicolumn{6}{|l|}{ Disease severity } \\
\hline \multirow[t]{8}{*}{ Mild (F0-F2) } & Absenteeism & 1197 & 358 & 1007 & [20] \\
\hline & Absenteeism & $221-5018$ & NR & 51 & [37] \\
\hline & Direct non-medical & 300 & NR & 166 & [43] \\
\hline & Indirect & 838 & NR & 166 & [43] \\
\hline & Patient time & 1015-2062 & NR & 326 & [46] \\
\hline & Caregiver time & $25-107$ & NR & 326 & {$[46]$} \\
\hline & Caregiver time & 45 & NR & 652 & [33] \\
\hline & Travel & 218 & NR & 652 & [33] \\
\hline Moderate (F3) & Absenteeism & 1049-2713 & NR & 165 & [37] \\
\hline \multirow[t]{6}{*}{ Compensated cirrhosis $(\mathrm{F} 4)$} & Absenteeism & 874 & 478 & 87 & [20] \\
\hline & Absenteeism & $732-5520$ & NR & 67 & [37] \\
\hline & Direct non-medical & 706 & NR & 24 & [43] \\
\hline & Indirect & 1016 & NR & 24 & [43] \\
\hline & Caregiver & 156 & NR & 222 & [33] \\
\hline & Travel & 652 & NR & 222 & [33] \\
\hline \multirow[t]{2}{*}{ Decompensated cirrhosis } & Absenteeism & 1616 & 346 & 256 & [20] \\
\hline & Absenteeism & $73-716$ & NR & 32 & [37] \\
\hline \multirow[t]{7}{*}{ Hepatocellular carcinoma } & Absenteeism & 4291 & 2388 & 17 & [20] \\
\hline & Caregiver time & 159 & NR & 85 & [33] \\
\hline & Caregiver time & $0-2558$ & NR & 21 & [46] \\
\hline & Direct non-medical & 1081 & NR & 10 & [43] \\
\hline & Indirect & 1703 & NR & 10 & [43] \\
\hline & Patient time & $1060-4915$ & NR & 21 & [46] \\
\hline & Travel & 701 & NR & 85 & [33] \\
\hline \multirow[t]{3}{*}{ Liver transplant (year 1) } & Absenteeism & 3343 & 1433 & 19 & {$[20]$} \\
\hline & Caregiver time & $0-5433$ & NR & 47 & [46] \\
\hline & Patient time & $3258-17,280$ & NR & 47 & {$[46]$} \\
\hline Liver transplant ( $>1$ year) & NR & NR & NR & NR & \\
\hline
\end{tabular}

$H C V$ hepatitis C virus, $N R$ not reported, $S D$ standard deviation, $S E$ standard error, $S V R$ sustained virologic response, USD US dollar been generally acceptable in HCV CEA modeling due to a large meta-analysis of disease progression based on this scoring system and the common use of fibrosis scores for clinical trial reporting [7, 52]. Modelers sourcing transition probabilities from the Thein et al. meta-analysis must then apply costs from sources that group F0-F2 ("mild") or even F0-F3 ("non-cirrhotic") [52]. Whether or not this modeling decision influences CEA results has not been evaluated to our knowledge.
In terms of types of costs, we found a broad range of costs covering what could be included in both health sector and societal perspective CEAs. Formal health care costs were frequently reported as "all medical," which may include a range of services, including inpatient, outpatient, laboratory, or other direct services captured under the medical benefit. Some studies stratified these formal health care costs into inpatient, outpatient, and pharmacy. We did not identify costs specific to laboratory costs that were not rolled into 
Table 5 Analyses of key variables by the presence of societal costs in included articles

\begin{tabular}{|c|c|c|c|c|c|}
\hline \multirow[t]{2}{*}{ Variable } & \multicolumn{2}{|c|}{$\begin{array}{l}\text { Societal costs } \\
(N=11)\end{array}$} & \multicolumn{2}{|c|}{$\begin{array}{l}\text { No societal costs } \\
(N=20)\end{array}$} & \multirow[t]{2}{*}{$P$ value* } \\
\hline & $N$ & $\%$ & $N$ & $\%$ & \\
\hline \multicolumn{6}{|l|}{ Country } \\
\hline US & 2 & 18 & 11 & 55 & 0.066 \\
\hline Other & 9 & 82 & 9 & 45 & \\
\hline \multicolumn{6}{|l|}{ Industry funding } \\
\hline Yes & 6 & 55 & 11 & 55 & 1.0 \\
\hline No & 5 & 45 & 9 & 45 & \\
\hline \multicolumn{6}{|l|}{ Costing method } \\
\hline Simple & 5 & 45 & 10 & 50 & 1.0 \\
\hline Complex & 6 & 55 & 10 & 50 & \\
\hline \multicolumn{6}{|l|}{ Risk of bias } \\
\hline High & 4 & 36 & 11 & 55 & 0.46 \\
\hline Moderate/low & 7 & 64 & 9 & 45 & \\
\hline
\end{tabular}

*Significance level $P<0.05$

the broader medical cost category. In terms of informal health costs, time (both patient and caregiver) and travel costs related to care were identified. The only non-health costs identified in articles included in our study were related to absenteeism and presenteeism. To our knowledge, when considering the International Society for Pharmacoeconomics and Outcomes Research (ISPOR) Special Task Force on value assessment, several elements of value described by Lakdawalla et al. have not been evaluated in the context of HCV [53]. When engaging HCV patients directly through qualitative interviews, advisory boards, focus groups, or Delphi panels, many patients report concerns that are difficult to measure in an observational study, such as impact on relationships, fear of harming others, financial stress, insurance issues, or stigma [54-57]. It may be difficult for researchers to accurately capture and quantify the real-world costs of some of these components reported by patients and attribute causality to $\mathrm{HCV}$ infection, leaving many of these constructs out of CEA designs [58].

Another area of concern for COI and CEA research in $\mathrm{HCV}$ was the use of list prices of drugs or hospital charges to estimate costs rather than determine an estimated net price actually paid by payers [20, 32, 42, 47, 59]. If CEA studies in HCV apply inflated disease costs without discounts to health states and use net drug prices (an estimated cost less than wholesale acquisition cost) for DAA treatment, the incremental cost of treatment may appear more favorable. Consistency in the approach for costing of the treatment, comparator, and health states may provide less chance of bias for incremental analyses, but having transparent net prices across the board to compare would be ideal.
The costing and analysis approaches described by articles included in this review demonstrate the heterogeneity in two of the most important research decisions made when conducting a COI analysis. Many researchers exploring COI make methodological decisions specific to answering a more narrow research question, and while these methods may be appropriate for the major question in the publication, the methods selected may present sources of bias for the health economists that seek to use these results to model a different question. There is nothing inherently wrong with any specific costing or analytical approach in a COI study, but the methods should be fit for purpose. Additionally, assessing the risk of bias for $\mathrm{COI}$ estimates can be quite challenging, as several factors may contribute to the direction or magnitude of bias. For example, a COI study using observational data failing to account for common sources of bias (e.g., selection bias, censoring, drug pricing discounts) may create both overestimation and underestimation problems. At the very least, economic modelers should attempt to qualitatively evaluate the potential bias for each input and then quantitatively account for the bias through thorough sensitivity and scenario analyses [60].

Future areas of research for the COI of HCV may consider ways to quantify the dynamic nature of $\mathrm{HCV}$ and the interactions of individuals in a population. Additionally, the psychosocial complexity of the disease warrants further investigation into extrahepatic manifestations, such as anxiety or depression. With highly effective treatments helping more patients reach SVR, we now have more opportunities to observe the post-SVR experience, which may inform costs and health effects for the post-SVR health state and re-infection transition probabilities for Markov-based modeling approaches in HCV infection. Currently, very few cost estimates have been reported on post-SVR, and we anticipate this to change over the next few years.

This systematic review had a few limitations that readers should consider. First, we focused on real-world evidence reporting costs, which eliminated any modeling approaches to estimate COI. Modeling costs may help provide estimates where current gaps exist or where real-world observational analyses are not feasible; however, we determined the potential methodological considerations for modeling costs were beyond the scope of this review and were covered previously by Chhatwal et al. [7]. We also focused our search on studies that were included in the "cost of illness" paradigm rather than more broadly including any study that mentioned "costs," as we aimed to compare studies with specific economic evaluation methods. Additionally, a majority of studies originated in the USA where costs may differ significantly from other international sites due to differences in pricing and health care system structure. Another limitation of this review is that we focused on full manuscripts, 
excluding posters or conference abstracts. Due to the indepth review and assessment of costing methods, we felt full manuscripts were necessary for appropriate evaluation. Finally, our assessment of risk of bias was reported for each study, but we did not quantitatively adjust cost estimates reported by each study outside of the currency and inflation conversions. We recognize that many cost estimates may be biased above or below the true costs, and we recommend any CEA researchers using this review to consider the costs we identified, costing methods used, and bias assessment all in the context of the specific research questions in their analyses.

\section{Conclusions}

Several observational studies capturing costs associated with $\mathrm{HCV}$ were identified in this review. Cost estimates for formal, informal, and non-health care services have been observed in HCV, but several challenges still exist in quantifying the full disease burden. These results showed significant heterogeneity in identification of all medical, inpatient, outpatient, pharmacy, and other direct and indirect costs associated with HCV infection. While there was no significant difference in risk of bias, comparing high versus low in the studies reviewed, future modeling exercises using realworld cost inputs should critically evaluate the risk of bias based on costing methods and data sources used and adjust their models accordingly.

Author Contributions Study concept and design: all authors; drafting of manuscript: TJM; critical reviews: all authors; statistical analysis: TJM; interpretation of data: all authors; final version approval: all authors.

Data Availability All data generated or analyzed during this study are included in this published article (and its supplementary information files).

\section{Compliance with Ethical Standards}

Funding No financial support was received for this work.

Conflict of interest TJM reports consultant fees from G\&W Labs, BMS, PhRMA, and NHC, all unrelated to this research; BLL reports a research grant from the American Cancer Society (IRG-17-179-04), unrelated to this work; BK reports no conflict of interest.

Open Access This article is licensed under a Creative Commons Attribution-NonCommercial 4.0 International License, which permits any non-commercial use, sharing, adaptation, distribution and reproduction in any medium or format, as long as you give appropriate credit to the original author(s) and the source, provide a link to the Creative Commons licence, and indicate if changes were made. The images or other third party material in this article are included in the article's Creative Commons licence, unless indicated otherwise in a credit line to the material. If material is not included in the article's Creative Commons licence and your intended use is not permitted by statutory regulation or exceeds the permitted use, you will need to obtain permission directly from the copyright holder. To view a copy of this licence, visit http://creativecommons.org/licenses/by-nc/4.0/.

\section{References}

1. Petruzziello A, Marigliano S, Loquercio G, Cozzolino A, Cacciapuoti C. Global epidemiology of hepatitis $\mathrm{C}$ virus infection: an up-date of the distribution and circulation of hepatitis $\mathrm{C}$ virus genotypes. World J Gastroenterol. 2016;22:7824-40.

2. Chou R, Hartung D, Rahman B, Wasson N, Cottrell EB, Ru R. Comparative effectiveness of antiviral treatment for hepatitis $\mathrm{C}$ virus infection in adults: a systematic review. Ann Intern Med. 2013;158:114-23.

3. Jakobsen JC, Nielsen EE, Feinberg J, et al. Direct-acting antivirals for chronic hepatitis C. Cochrane Database Syst Rev. 2017;6(6):CD012143.

4. Kohli A, Shaffer A, Sherman A, Kottilil S. Treatment of hepatitis C: a systematic review. JAMA. 2014;312:631-40.

5. Ward JW, Mermin JH. Simple, effective, but out of reach? Public health implications of HCV drugs. N Engl J Med. 2015;373:2678-80.

6. Chhatwal J, Kanwal F, Roberts MSMS, Dunn MAMA. Costeffectiveness and budget impact of hepatitis $\mathrm{C}$ virus treatment with sofosbuvir and ledipasvir in the United States. Ann Intern Med. 2015;162:397-406.

7. Chhatwal J, He T, Lopez-Olivo MA. Systematic review of modelling approaches for the cost effectiveness of hepatitis $\mathrm{C}$ treatment with direct-acting antivirals. Pharmacoeconomics. 2016;34:551-67.

8. Rice DP. Estimating the cost of illness. Am J Public Health. 1967;57:424-40.

9. Larg A, Moss JR. Cost-of-illness studies: a guide to critical evaluation. Pharmacoeconomics. 2011;29:653-71.

10. Bloom BS, de Pouvourville N, Straus WL. Cost of illness of Alzheimer's disease: how useful are current estimates? Gerontologist. 2003;43:158-64.

11. Tarricone R. Cost-of-illness analysis. What room in health economics? Health Policy (New York). 2006;77:51-63.

12. Akobundu E, Ju J, Blatt L, Mullins CD. Cost-of-illness studies: a review of current methods. Pharmacoeconomics. 2006;24:869-90.

13. Onukwugha E, McRae J, Kravetz A, Varga S, Khairnar R, Mullins CD. Cost-of-Illness studies: an updated review of current methods. Pharmacoeconomics. 2015;34:43-58.

14. Mattingly TJ II, Mullins CD, Onukwugha E, Mattingly TJ, Mullins CD, Onukwugha E. Publication of cost-of-illness studies: does methodological complexity matter? Pharmacoeconomics. 2016;34:1067-70.

15. Moher D, Liberati A, Tetzlaff J, Altman DG, The PRISMA Group. Preferred reporting items for systematic reviews and meta-analyses: the PRISMA statement. PLoS Med. 2009;6:e1000097.

16. Basu A. Estimating costs and valuations of non-health benefits in cost-effectiveness analysis. In: Neumann PJ, Sanders GD, Russell LB, Siegel JE, Ganiats TG, editors. Cost-effectiveness health and medicine. New York: Oxford University Press; 2017. p. 201-235.

17. U.S. Bureau of Labor Statistics. Measuring price change in the CPI: medical care [Internet]. 2020. https://www.bls.gov/cpi/facts heets/medical-care.htm. Accessed 19 Jan 2020

18. R Core Team. R: a language and environment for statistical computing [Internet]. Vienna, Austria: R Foundation for Statistical Computing; 2020. https://www.r-project.org. Accessed 24 May 2020. 
19. Abergel A, Rotily M, Branchoux S, Akremi R, de Léotoing L, Vainchtock A, et al. Chronic hepatitis C: burden of disease and cost associated with hospitalisations in France in 2012 (The HEPC-LONE study). Clin Res Hepatol Gastroenterol. 2016;40:340-8.

20. Baran RW, Samp JC, Walker DR, Smeeding JE, Young JW, Kleinman NL, et al. Costs and absence of HCV-infected employees by disease stage. J Med Econ. 2015;18:691-703.

21. Ki M, Choi HY, Kim KA, Jang ES, Jeong SH. Healthcare costs for chronic hepatitis C in South Korea from 2009 to 2013: an analysis of the national health insurance claims' data. Gut Liver. 2017;11:835-42.

22. Kieran JA, Norris S, O'Leary A, Walsh C, Merriman R, Houlihan $\mathrm{D}$, et al. Hepatitis $\mathrm{C}$ in the era of direct-acting antivirals: real-world costs of untreated chronic hepatitis $\mathrm{C}$; a cross-sectional study. BMC Infect Dis. 2015;15:1-9.

23. Krajden M, Kuo M, Zagorski B, Alvarez M, Yu A, Krahn M. Health care costs associated with hepatitis $\mathrm{C}$ : a longitudinal cohort study. Can J Gastroenterol. 2010;24:717-26.

24. Mattingly TJ II, Pandit NS, Onukwugha E. Burden of co-infection: a cost analysis of human immunodeficiency virus in a commercially insured hepatitis $C$ virus population. Infect Dis Ther. 2019;8:219-28.

25. Menzin J, White LA, Nichols C, Deniz B. The economic burden of advanced liver disease among patients with hepatitis $\mathrm{C}$ virus: a large state Medicaid perspective. BMC Health Serv Res. 2012;12:459

26. Nevens F, Colle I, Michielsen P, Robaeys G, Moreno C, Caekelbergh $\mathrm{K}$, et al. Resource use and cost of hepatitis C-related care. Eur J Gastroenterol Hepatol. 2012;24:1191-8.

27. Park H, Jeong D, Nguyen P, Henry L, Hoang J, Kim Y, et al. Economic and clinical burden of viral hepatitis in California: a population-based study with longitudinal analysis. PLoS One. 2018;13:1-13.

28. Pascual-Argente N, Puig-Junoy J, Llagostera-Punzano A. Nonhealthcare costs of hepatitis C: a systematic review. Expert Rev Gastroenterol Hepatol. 2018;12(1):19-30.

29. Perrone V, Sangiorgi D, Buda S, Degli EL. Disease progression and health care resource consumption in patients affected by hepatitis $\mathrm{C}$ virus in real practice setting. Clin Outcomes Res. 2016;8:591-7.

30. Pham TT, Keast SL, Farmer KC, Thompson DM, Rathbun RC, Nesser NJ, et al. Sustained virologic response and costs associated with direct-acting antivirals for chronic hepatitis $\mathrm{C}$ infection in Oklahoma Medicaid. J Manag Care Spec Pharm. 2018;24:664-76.

31. Bichoupan K, Martel-Laferriere V, Sachs D, Ng M, Schonfeld EA, Pappas A, et al. Costs of telaprevir-based triple therapy for hepatitis C: $\$ 189,000$ per sustained virological response. Hepatology. 2014;60:1187-95.

32. Reau N, Vekeman F, Wu E, Bao Y, Gonzalez YS. Prevalence and economic burden of extrahepatic manifestations of hepatitis $\mathrm{C}$ virus are underestimated but can be improved with therapy. Hepatol Commun. 2017;1:439-52.

33. Scalone L, Fagiuoli S, Ciampichini R, Gardini I, Bruno R, Pasulo $\mathrm{L}$, et al. The societal burden of chronic liver diseases: results from the COME study. BMJ Open Gastroenterol. 2015;2:e000025.

34. Shon C, Choi HY, Shim JJ, Park SY, Lee KS, Yoon SJ, et al. The economic burden of hepatitis A, B, and C in South Korea. Jpn J Infect Dis. 2016;69:18-27.

35. Solid CA, Peter SA, Natwick T, Guo H, Collins AJ, Arduino JM. Impact of renal disease on patients with hepatitis $C$ : a retrospective analysis of disease burden, clinical outcomes, and health care utilization and cost. Nephron. 2017;136:54-61.

36. Solomon M, Bonafede M, Pan K, Wilson K, Beam C, Chakravarti $\mathrm{P}$, et al. Direct medical care costs among pegylated interferon plus ribavirin-treated and untreated chronic hepatitis $\mathrm{C}$ patients. Dig Dis Sci. 2011;56:3024-31.

37. Stahmeyer JT, Rossol S, Bert F, Antoni C, Demir M, Hinrichsen $\mathrm{H}$, et al. Cost of treating hepatitis $\mathrm{C}$ in Germany: a retrospective multicenter analysis. Eur J Gastroenterol Hepatol. 2014;26:1278-85.

38. Tandon N, Balart LA, Laliberté F, Pilon D, Lefebvre P, Germain $\mathrm{G}$, et al. Impact of completing chronic hepatitis $\mathrm{C}(\mathrm{CHC})$ treatment on post-therapy healthcare cost. J Med Econ. 2014;17:862-71.

39. Tapper EB, Catana AM, Sethi N, Mansuri D, Sethi S, Vong A, et al. Direct costs of care for hepatocellular carcinoma in patients with hepatitis C cirrhosis. Cancer. 2016;122:852-8.

40. Vahedi M, Pourhoseingholi A, Ashtari S, Pourhoseingholi MA, Karkhane M, Moghimi-Dehkordi B, et al. Using statistical models to assess medical cost of hepatitis $\mathrm{C}$ virus. Gastroenterol Hepatol from Bed to Bench. 2012;5:31-6.

41. Vietri J, Prajapati G, El Khoury AC. The burden of hepatitis C in Europe from the patients' perspective: a survey in 5 countries. BMC Gastroenterol. 2013;13:16.

42. Brook RA, Kleinman NL, Su J, Corey-Lisle PK, Iloeje UH. Absenteeism and productivity among employees being treated for hepatitis C. Am J Manag Care. 2011;17:657-64.

43. Zare F, Fattahi MR, Sepehrimanesh M, Safarpour AR. Economic burden of hepatitis $\mathrm{C}$ virus infection in different stages of disease: a report from southernIran. Hepat Mon. 2016;16(4):e32654.

44. Castelo A, Brandão Mello CE, Teixeira R, Madruga JVR, Reuter T, Pereira LMMB, et al. Hepatitis $\mathrm{C}$ in the Brazilian public health care system: Burden of disease. Arq Gastroenterol. 2018;55:329-37.

45. El Khoury AC, Wallace C, Klimack WK, Razavi H. Economic burden of hepatitis C-associated diseases: Europe, Asia Pacific, and the Americas. J Med Econ. 2012;15:887-96.

46. Federico CA, Hsu PC, Krajden M, Yoshida EM, Bremner KE, Weiss AA, et al. Patient time costs and out-of-pocket costs in hepatitis C. Liver Int. 2012;32:815-25.

47. Galbraith JW, Donnelly JP, Franco RA, Overton ET, Rodgers JB, Wang HE. National estimates of healthcare utilization by individuals with hepatitis $\mathrm{C}$ virus infection in the United States. Clin Infect Dis. 2014;59:755-64.

48. Helsper CW, Hellinga HL, van Essen GA, de Wit GA, Bonten MJM, van Erpecum KJ, et al. Real-life costs of hepatitis C treatment. Neth J Med. 2012;70:145-53.

49. Karahasanoğlu FB, Asan A, Sacar S, Turgut H. Costs of treatment, follow-up, and complications of chronic hepatitis B and hepatitis C infections. Balk Med J. 2013;30:375-81.

50. Bedossa P, Poynard T. An algorithm for the grading of activity in chronic hepatitis C. The METAVIR Cooperative Study Group. Hepatology. 1996;24:289-93.

51. Neumann PJ, Sanders GD, Russell LB, Siegel JE, Ganiats TG, editors. Cost-effectiveness in health and medicine. 2nd ed. New York: Oxford University Press; 2017.

52. Thein HH, Yi Q, Dore GJ, Krahn MD. Estimation of stage-specific fibrosis progression rates in chronic hepatitis $\mathrm{C}$ virus infection: a meta-analysis and meta-regression. Hepatology. 2008;48:418-31.

53. Lakdawalla DN, Doshi JA, Garrison LP, Phelps CE, Basu A, Danzon PM. Defining elements of value in health care-a health economics approach: an ISPOR Special Task Force report [3]. Value Health. 2018;21:131-9.

54. Mattingly TJ II, Slejko JF, Perfetto EM, Kottilil S, Mullins CD. What matters most for treatment decisions in hepatitis C: effectiveness, costs, and altruism. Patient. 2019;12:631-8.

55. Sublette VA, Smith SK, George J, McCaffery K, Douglas MW. The Hepatitis C treatment experience: patients' perceptions of the facilitators of and barriers to uptake, adherence and completion. Psychol Health. 2015;30:987-1004. 
56. Armstrong AR, Herrmann SE, Chassany O, Lalanne C, Da Silva $\mathrm{MH}$, Galano E, et al. The international development of PROQOL-HCV: an instrument to assess the health-related quality of life of patients treated for Hepatitis C virus. BMC Infect Dis. 2016;16:443.

57. Harris M, Rhodes T. Caring and curing: Considering the effects of hepatitis $\mathrm{C}$ pharmaceuticalisation in relation to non-clinical treatment outcomes. Int J Drug Policy. 2018;60:24-322.

58. Mattingly II TJ, Slejko JF, Onukwugha E, Perfetto EM, Kottilil S, Mullins CD. Value in hepatitis $\mathrm{C}$ virus treatment: a patient-centered cost-effectiveness analysis. Pharmacoeconomics [Internet]. 2019; 1-10. https://rdcu.be/bYbA7. Accessed 9 Jan 2020
59. Mattingly TJ II, Levy JF, Slejko JF, Onwudiwe NC, Perfetto EM. Estimating drug costs: how do manufacturer net prices compare with other common US price references? Pharmacoeconomics. 2018;36:1093-9.

60. Caro JJ, Briggs AH, Siebert U, Kuntz KM, ISPOR-SMDM Modeling Good Research Practices Task Force. Modeling good research practices-overview: a report of the ISPOR-SMDM Modeling Good Research Practices Task Force-1. Med Decis Mak. 2012;15:796-803.

61. mapchart.net. World map [Internet]. https://mapchart.net/. Accessed 9 Feb 2020 